\title{
SISTEM PAKAR UNTUK MENDIAGNOSA HAMA PENYAKIT TANAMAN AGLAONEMA
}

\author{
Ratih Agustina Imaniar ${ }^{1}$ \\ ${ }^{1}$ Teknik Informatika STMIK Hang Tuah Pekanbaru \\ Jl. Mustafa Sari No.5 Pekanbaru Riau \\ Email : ummuziad@ymail.com
}

\begin{abstract}
ABSTRAK
Sistem Pakar Untuk Mendiagnosa Hama Penyakit Tanaman Aglaonema, ini dibuat dengan tujuan agar dapat menangani gangguan atau kerusakan tanaman Aglaonema akibat serangan hama maupun penyakit, sehingga sistem ini dapat berperan layaknya seorang pakar yang ahli dalam bidang tanaman hias, terutama tanaman Aglaonema. Sistem Pakar ini menggunakan metode penelusuran forward chaining, yaitu pembuatan sistem pakar ini dimulai dengan mendeklarasikan dahulu pertanyaan-pertanyaan dari permasalahan sistem pakar untuk kemudian dari pertanyaan tersebut mendasari adanya kesimpulan dari analisa permasalahan.

Sebelum sistem pakar dibangun, perlu mengidentifikasi dahulu permasalahan yang ada, kemudian setelah permasalahan diketahui perlu adanya identifiaksi kebutuhan software dan hardware. Dalam pengembangan selanjutnya struktur basis data perlu dipersiapkan untuk memulai pembuatan sistem pakar ini. Perlu adanya pengujian terhadap sistem pakar yang telah dibuat sehingga dapat diketahui adanya kesalahan yang mungkin terjadi pada saat pengembangan sistem pakar ini. Pengujian yang dilakukan bertujuan untuk mencari perbandingan kecepatan antara sistem yang berjalan langsung dengan sistem yang sistem yang berjalan lewat program sistem pakar.

Setelah semua tahapan dilakukan, maka perlu adanya suatu langkah untuk menyimpulkan dan memberi saran terhadap pengembangan sistem pakar ini sehingga dapt memberikan masukan terhadap pengembangan sistem pakar selanjutnya.
\end{abstract}

Kata Kunci : Hama Penyakit Aglaonema, Sistem Pakar, Forward Chaining

\begin{abstract}
Expert System for Diagnosing Plant Diseases Pests Aglaonema ", was made in order to handle the disturbance or damage caused Aglaonema plant pests and diseases, so the system can act as an expert who is an expert in the field of ornamental plants, particularly Aglaonema plant. The expert system uses a forward chaining search method, namely the manufacture of this expert system begins by declaring the questions of an expert system for later issues of the question underlying the conclusions of the analysis of the problem. Before the expert system is built, it is necessary first to identify existing problems, then after a problem is known to the Identification of software and hardware needs. In a further development of database structures need to be prepared to begin the manufacture of this expert system. Need for examination of an expert system that has been made so as to note any errors that may occur during the development of this expert system. Tests are performed aiming to find a speed comparison between systems that run the system di-
\end{abstract}


rectly to the system that runs through the expert system program. After all stages is done, it needs to be a step to conclude and give suggestions to the development of this expert system that can provide input to the further development of expert systems.

Key Words : Plant Diseases, Expert System,

\section{PENDAHULUAN}

Dunia hobi dan bisnis tanaman hias nyaris tak pernah surut. Bahkan cenderung terus berkembang. Sepanjang tahun, tren tanaman hias silih berganti. Salah satu tanaman yang menjadi primadona tanaman hias adalah Aglaonema. Perputaran bisnis tanaman hias dari keluarga Araceae ini melesat begitu cepat. Pamornya menajak dan harganya melejit hingga jutaan rupiah. Kehadiran varian-varian baru dari tanaman ini juga kian mendongkrak popularitas Aglaonema. Banyak pengusaha tanaman hias menuai untung dari bisnis tanaman pembawa rejeki itu. Fenomena yang kemudian terjadi adalah lahirnya "pemain baru" baik didalam maupun luar negeri yang ikut menekuni bisnis ini. Mereka tergiur keuntungan yang ditawarkan oleh tanaman ini. Bahkan tidak sedikit yang menganggap bahwa tanaman ini merupakan "barang investasi" yang bernilai tinggi. Anggapan ini muncul karena tanaman ini akan terus menghiasi tren tanaman hias, dan banyak yang berburu tanaman ini.

Daya tarik Aglaonema terletak pada keelokan corak daun yang berkolaborasi dengan kilauan warnanya. Walau terkesan menggiurkan, bukan berarti bisnis Aglaonema tanpa batu sandungan. Salah satu masalah yang sering terjadi adalah serangan hama penyakit. Hama penyakit itu menyerang tanpa pandang bulu, Aglaonema standar maupun yang eksklusif seharga puluhan juta rupiah pun diserangnya. Banyak fenomena yang terjadi pada petani maupun pebisnis Aglaonema yang kurang memahami hama penyakit tanaman ini. Terlebih bagi para "pemain baru" yang kecenderungan dari mereka hanya "latah" berbisnis tanaman ini. Permasalahan yang kemudian muncul adalah kualitas tanaman yang menjadi rendah, bahkan kematian. Hal itu tentu saja menyebabkan kerugian yang tidak sedikit nominalnya.

Perkembangan teknologi yang melaju pesat, berbanding lurus dengan perkembangan dibidang komputer. Berbagai inovasi terus dikembangkan demi meningkatkan peran dan kinerja komputer. Salah satu sistem yang diadopsi teknologi komputer untuk digunakan sebagai pendiagnosa hama dan penyakit tanaman Aglaonema adalah sistem pakar. Sistem yang merupakan bagian dari kecerdasan buatan ini, merupakan suatu program komputer cerdas yang menggunakan knowledge (pengetahuan) dan prosedur inferensi untuk menyelasaikan masalah yang cukup sulit sehingga membutuhkan seorang ahli untuk menyelesaikannya (Feigenbaum, 1982), dari pernyataan tersebut maka dapat diambil kesimpulan bahwa sistem pakar (expert system) adalah sistem yang berusaha mengadopsi pengetahuan manusia ke komputer, agar komputer dapat menyelesaikan masalah yang seperti biasa dilakukan oleh seorang ahli atau pakar. Permasalahan yang telah diuraikan di atas juga dapat segera diatasi, dengan memanfaatkan sistem pakar ini, yaitu dengan mengolah data-data hama penyakit tanaman Aglaonema. Fenomena ini yang menjadi alasan untuk melaksanakan penelitian dimana aplikasi ini nantinya diharapkan mampu untuk mengetahui gejala-gejala serangan hama penyakit secara dini, jenis hama penyakit, berikut solusi pemecahannya. Juga diharapkan kian memperkaya pengetahuan tentang hama penyakit tanaman Aglaonema bagi para pemilik, petani, kolektor, maupun pebisnis tanaman ini, tanpa harus berinteraksi dengan seorang pakar secara langsung. 


\section{DASAR TEORI}

\subsection{Sistem Pakar}

Sistem pakar adalah suatu program komputer yang dirancang untuk mengambil keputusan seperti keputusan yang diambil oleh seorang atau beberapa orang pakar. Menurut Marimin (1992), sistem pakar adalah sistem perangkat lunak komputer yang menggunakan ilmu, fakta, dan teknik berpikir dalam pengambilan keputusan untuk menyelesaikan masalah-masalah yang biasanya hanya dapat diselesaikan oleh tenaga ahli dalam bidang yang bersangkutan. Dalam penyusunannya, sistem pakar mengkombinasikan kaidah-kaidah penarikan kesimpulan (inference rules) dengan basis pengetahuan tertentu yang diberikan oleh satu atau lebih pakar dalam bidang tertentu. Kombinasi dari kedua hal tersebut disimpan dalam komputer, yang selanjutnya digunakan dalam proses pengambilan keputusan untuk penyelesaian masalah tertentu.

\subsection{Struktur Sistem Pakar}

Komponen utama pada struktur sistem pakar (Hu et al, 1987) meliputi:

\section{Basis Pengetahuan (Knowledge Base)}

Basis pengetahuan merupakan inti dari suatu sistem pakar, yaitu berupa representasi pengetahuan dari pakar. Basis pengetahuan tersusun atas fakta dan kaidah. Fakta adalah informasi tentang objek, peristiwa, atau situasi. Kaidah adalah cara untuk membangkitkan suatu fakta baru dari fakta yang sudah diketahui. Menurut Gondran (1986) dalam Utami (2002), basis pengetahuan merupakan representasi dari seorang pakar, yang kemudian dapat dimasukkan kedalam bahasa pemrograman khusus untuk kecerdasan buatan (misalnya PROLOG atau LISP) atau shell sistem pakar (misalnya EXSYS, PC-PLUS, CRYSTAL, dsb.)

\section{Mesin Inferensi (Inference Engine)}

Mesin inferensi berperan sebagai otak dari sistem pakar. Mesin inferensi berfungsi untuk memandu proses penalaran terhadap suatu kondisi, berdasarkan pada basis pengetahuan yang tersedia. Di dalam mesin inferensi terjadi proses untuk memanipulasi dan mengarahkan kaidah, model, dan fakta yang disimpan dalam basis pengetahuan dalam rangka mencapai solusi atau kesimpulan. Dalam prosesnya, mesin inferensi menggunakan strategi penalaran dan strategi pengendalian.

Strategi penalaran terdiri dari strategi penalaran pasti (Exact Reasoning) dan strategi penalaran tak pasti (Inexact Reasoning). Exact reasoning akan dilakukan jika semua data yang dibutuhkan untuk menarik suatu kesimpulan tersedia, sedangkan inexact reasoning dilakukan pada keadaan sebaliknya.

Strategi pengendalian berfungsi sebagai panduan arah dalam melakukan prose penalaran. Terdapat tiga tehnik pengendalian yang sering digunakan, yaitu forward chaining, backward chaining, dan gabungan dari kedua tehnik pengendalian tersebut.

\section{Basis Data (Database)}

Basis data terdiri atas semua fakta yang diperlukan, dimana fakta-fakta tersebut digunakan untuk memenuhi kondisi dari kaidah-kaidah dalam sistem. Basis data menyimpan semua fakta, baik fakta awal pada saat sistem mulai beroperasi, maupun faktafakta yang diperoleh pada saat proses penarikan kesimpulan sedang dilaksanakan. Basis data digunakan untuk menyimpan data hasil observasi dan data lain yang dibutuhkan selama pemrosesan.

4. Antarmuka Pemakai (User Interface)

Fasilitas ini digunakan sebagai perantara komunikasi antara pemakai dengan sistem. 
Hubungan antar komponen penyusun struktur sistem pakar dapat dilihat pada Gambar di bawah ini :

\subsection{Karakteristik dan Komponen Dasar dari Sistem Pakar}

Beberapa karakteristik dari sistem pakar:

1. Memiliki high performance. Sistem pakar tersebut haruslah mampu merespon dengan tingkat kompetensi yang sama atau lebih baik dari tenaga ahli di lapangan.

2. Memiliki waktu respon yang lebih singkat dari tenaga ahli.

3. Keputusan yang diambil dapat dipercaya.

4. Keputusan yang diambil dapat dipertanggung jawabkan, karena disertai dengan alasan- alasru). yang detil, kenapa keputusan itu yang diambil.

\subsection{Metode Backword dan Forward Chaining}

Metode backward chaining merupakan kebalikan dari metode forward chaining dan sering disebut penalaran mundur (Kusrini 2006: 36). Menurut Schnupp dalam Kusrini (2008: 11) metode backward chaining (runut balik) merupakan metode yang cocok digunakan dalam memecahkan masalah diagnosis. Dalam metode backward chaining (runut balik), penalaran dimulai dengan tujuan merunut balik ke jalur yang akan mengarahkan ke tujuan tersebut menurut Giarattano dan Riley dalam (Kusrini, 2006: 36). Menurut Irawan (2007: 35) metode forward chaining adalah suatu metode dari inference engine untuk memulai penalaran atau pelacakan suatu data dari fakta-fakta yang ada menuju suatu kesimpulan. Menurut Wilson dalam Kusrini (2008: 8) metode forward chaining (runut maju) merupakan suatu metode yang menggunakan himpunan aturan kondisi-aksi. Dalam metode ini, kaidah interpreter mencocokkan fakta atau statement dalam pangkalan data dengan situasi yang dinyatakan dalam bagian sebelah kiri atau kaidah if.

\subsection{Tanaman Aglaonema}

Tanaman hias aglaonema di Indonesia tidak terlepas dari satu nama pecinta tanaman hias bernama Gregorius Granadi Hambali atau yang lebih dikenal sebagai Greg Hambali. Beliau adalah seorang tokoh yang sangat disegani di kalangan kolektor tanaman hias karena karyanya yang sangat luar biasa. Beliau berhasil menyilangkan tanaman aglaonema dan menciptakan beberapa varietas baru seperti Pride of Sumatra, Tiara, Widuri, Hot Lady, dan Harlequin.

Kerja keras Greg di bidang penyilangan aglaonema membuahkan hasil yang cukup mencengankan terutama bagi masyarakat kebanyakan. Bayangkan, harga jual dari hasil penyilangan pertama Harlequin adalah lebih dari Rp 600 juta melalui lelang yang dimenangkan oleh Harry Setiawan, pemilik Irene Flora di Jakarta Timur. Selain itu, harga aglaonema Tiara hasil silangannya sempat mencapai Rp 3 juta per lembar daun yang merupakan harga yang cukup fantastis untuk tanaman hias. Saat ini, tanaman hias aglaonema tidak lagi semahal beberapa waktu yang lalu. Beragam jenis aglaonema telah banyak tersedia di pasaran dengan harga yang terjangkau sehingga anda dapat mengoleksinya tanpa harus merogoh kocek terlalu dalam. Pada umumnya, aglaonema dapat dibedakan menjadi lima jenis berbeda jika kita merujuk pada warna dasar daunnya. Lima jenis warna tersebu adalah hujau, kuning, merah, putih, dan corak. Berikut beberapa jenis aglaonema yang cukup populer saat ini.

a. Aglaonema Brevispathum 
b. Aglaonema Commutatum

○ Triubii

- Tricolor

- Silver

c. Aglaonema Costatum

- Foxii

d. Aglaonema Virescens

e. Aglaonema Cuscuria

\subsection{Hama Tanaman Aglaonema}

\section{a. Hama}

Hama adalah hewan penggangu tanaman yang secara fisik masih dapat dilihat secara kasat mata tanpa bantuan alat . Hama pada aglaonema bermacam-macam dan gejalanya berbeda-beda . Setiap hama memiliki cara penanggulangan tersendiri .

\section{b. Kutu Putih / Kutu kebul}

Kutu ini lebih banyak menyerang aglaonema di daratan rendah dibanding dengan di dataran tinggi . Kutu putih Whitefly ini dapat ditemukan di batang dan daun bagian bawah . Kutu tersebut mengisap cairan daun dan meninggalkan jelaga pada daun . Hama ini dapat ditanggulangi dengan membersihkannya dengan kapas yang telah dicelupkan insektisida encer. Setelah itu, daun disemprot kembali dengan insektisida . Insektisida kontak atau sismetik yang bias digunakan, Mitac $200 \mathrm{EC}$ dosis 1-2ml/1, dan Confidor 200 SL dosis $1 \mathrm{ml} / 1$.

c. Ulat

Hama ulat ada yang menyerang daun, yaitu Spodoptera sp ., ditandai dengan daun muda atau setengah tua yang rombeng dari pinggir. Ada juga ulat yang menyerang batang, yaitu Noctuidae. Penanggulangannya dapat dilakukan dengan mengambil ulat secara mekanis. Namun, bila jumlahnya sudah banyak, ulat dapat dibasmi dengan menyemprotkan insektisida 2 minggu sekali . Insektisida yang dapat digunakan adalah Decis 25 CE 0,5-1 ml/1, Atabron $1 \mathrm{ml} / 1$, atau Buldok 25 EC dosis 0,5-2 $\mathrm{ml} / \mathrm{l}$.

\section{d. Belalang}

Gejala penyerangan hama belalang ini sama dengan ulat, yaitu daun menjadi rombeng. Hama ini dapat ditanggulangi dengan penangkapan secara manual . Tangkap belalang yang belum bersayap atau saat masih pagi dan berembun biasanya belalang tidak dapat terbang dengan sayap basah. Anda juga dapat menyemprotkan Confidor $200 \mathrm{SL}$ dosis $1 \mathrm{ml} / 1$. Campurkan Decis 2,5 EC dosis 0,75-1 ml/l dengan frekuensi penyemprotan 2 minggu sekali .

\section{e. Kutu Perisai}

Hama ini menyerang bagian daun . Kutu ini biasanya terdapat koloni dengan membentuk barisan di bagian tulang daun . Sesuai namanya, kutu ini memiliki bentuk fisik seperti perisai pada punggungnya . Kutu perisai dapat diatasi menggunakan insektisida sistemik dengan bahan aktif acephate .

\section{f. Root Mealy Bugs}

Hama ini menyerang bagian akar tanaman, bentuknya seperti kutu putih . Tanaman menjadi kurus, kerdil, daunnya mengecil dan layu . Anda dapat menanggulangi dengan mengganti media tanam . Selain itu, gunakan insektisida Confidor 200 SL dosis $0,5-0,75 \mathrm{ml} / 1$ 


\section{g. Kutu Sisik}

Menyerang bagian daun, pelepah, batang dan bunga . Bentuknya seperti lintah dengan ukuran yang jauh lebih kecil . Kutu sisik dapat menyebabkan daun mengerut, kuning, layu , dan akhirnya mati . Anda juga dapat menyemprotkan insektisida Confidor 200-SL atau Agrimex $18 \mathrm{EC}$ dosis $1 \mathrm{ml} / /$ dengan frekuensi 1 minggu sekali.

Hama adalah hewan penggangu tanaman yang secara fisik masih dapat dilihat secara kasat mata tanpa bantuan alat . Hama pada aglaonema bermacam-macam dan gejalanya berbeda-beda . Setiap hama memiliki cara penanggulangan tersendiri .

\section{h. Kutu Putih / Kutu kebul}

Kutu ini lebih banyak menyerang aglaonema di daratan rendah dibanding dengan di dataran tinggi . Kutu putih Whitefly ini dapat ditemukan di batang dan daun bagian bawah . Kutu tersebut mengisap cairan daun dan meninggalkan jelaga pada daun . Hama ini dapat ditanggulangi dengan membersihkannya dengan kapas yang telah dicelupkan insektisida encer. Setelah itu, daun disemprot kembali dengan insektisida . Insektisida kontak atau sismetik yang bias digunakan, Mitac 200 EC dosis 1-2ml/1, dan Confidor 200 SL dosis 1 $\mathrm{ml} / \mathrm{l}$.

\section{i. Ulat}

Hama ulat ada yang menyerang daun, yaitu Spodoptera sp ., ditandai dengan daun muda atau setengah tua yang rombeng dari pinggir. Ada juga ulat yang menyerang batang, yaitu Noctuidae. Penanggulangannya dapat dilakukan dengan mengambil ulat secara mekanis . Namun, bila jumlahnya sudah banyak, ulat dapat dibasmi dengan menyemprotkan insektisida 2 minggu sekali . Insektisida yang dapat digunakan adalah Decis 25 CE 0,5-1 ml/l, Atabron $1 \mathrm{ml} / 1$, atau Buldok $25 \mathrm{EC}$ dosis 0,5-2 ml/1 .

\section{j. Belalang}

Gejala penyerangan hama belalang ini sama dengan ulat, yaitu daun menjadi rombeng . Hama ini dapat ditanggulangi dengan penangkapan secara manual . Tangkap belalang yang belum bersayap atau saat masih pagi dan berembun biasanya belalang tidak dapat terbang dengan sayap basah. Anda juga dapat menyemprotkan Confidor 200 SL dosis 1 $\mathrm{ml} / \mathrm{l}$. Campurkan Decis 2,5 EC dosis 0,75-1 ml/l dengan frekuensi penyemprotan 2 minggu sekali .

\section{k. Kutu Perisai}

Hama ini menyerang bagian daun . Kutu ini biasanya terdapat koloni dengan membentuk barisan di bagian tulang daun. Sesuai namanya, kutu ini memiliki bentuk fisik seperti perisai pada punggungnya . Kutu perisai dapat diatasi menggunakan insektisida sistemik dengan bahan aktif acephate .

\section{Root Mealy Bugs}

Hama ini menyerang bagian akar tanaman, bentuknya seperti kutu putih . Tanaman menjadi kurus, kerdil, daunnya mengecil dan layu . Anda dapat menanggulangi dengan mengganti media tanam. Selain itu, gunakan insektisida Confidor 200 SL dosis 0,5-0,75 $\mathrm{ml} / \mathrm{l}$ atau

\section{m. Kutu Sisik}

Menyerang bagian daun, pelepah, batang dan bunga . Bentuknya seperti lintah dengan ukuran yang jauh lebih kecil . Kutu sisik dapat menyebabkan daun mengerut, kuning, layu, dan akhirnya mati . Anda juga dapat menyemprotkan insektisida Confidor 200-SL atau Agrimex $18 \mathrm{EC}$ dosis $1 \mathrm{ml} / /$ dengan frekuensi 1 minggu sekali. 


\section{METODE PENELITIAN}

\section{a. Metode Interview}

Metode ini dilakukan dengan mengumpulkan data dengan cara melakukan tanya jawab secara langsung pada narasumber yaitu seorang pakar tanaman hias.

\section{b. Metode Observasi}

Observasi merupakan pengumpulan data melalui pengamatan terhadap gejala atau peristiwa yang diselidiki pada objek penelitian. Dalam penelitian ini, diamati secara langsung tanaman Aglaonema, serta gejala yang timbul akibat serangan hama penyakit. Pengamatan ini dilakukan langsung pada tempat dimana pakar melakukan aktifitas kepakarannya.

\section{c. Metode Studi Pustaka}

Studi pustaka merupakan metode pengumpulan data dengan menggunakan referensi buku-buku yang berkaitan dengan bidang kajian dari penelitian ini. Buku-buku yang menjadi referensi yaitu buku tentang sistem pakar, tanaman Aglaonema, serta buku tentang pemrograman visual basic 6.0.

\section{ANALISIS}

AI merupakan sistem dengan basis pengetahuan yang dinamis, dimana pengetahuan itu dapat beubah seiring dengan berjalannya waktu(teori certainty factor) sehingga harus dapat dilakukan pembaharuan seperti penambahan, penghapusan maupun perubahan terhadap data yang sudah disimpan sebelumnya tanpa harus mengubah isi dari program secara keseluruhan. Perubahan hanya dilakukan pada bagian basis pengetahuan saja sehingga aplikasi AI ini dapat dikembangankan lebih lanjut.Tahapan analisis terhadap suatu sistem dilakukan sebelum tahapan perancangan, hal ini agar perangkat lunak yang dirancang sesuai dengan masalah yang akan diselesaikan.

Proses yang terjadi pada sistem secara sederhana dapat dijelaskan, dimana pada proses diagnosa user akan dihadapkan pada pertanyaan dan setiap pertanyaan terdapat pilihan-pilihan gejala yang ditampilkan oleh sistem, setelah user memilih salah satu dari pilihan gejala yang disediakan, maka sistem akan membaca pilihan yang dimasukkan oleh user yang disesuaikan dengan aturan pada basis pengetahuan.Pada setiap aturan berisi solusi bernilai 0 (solusi=0) dan solusi berisi kode penyakit 001, 002, dan seterusnya (solusi=Kdpenyakit,misal solusi= 004). Solusi 0, sistem akan terus membaca aturan dan menampilkan pertanyaan beserta pilihan gejala selanjutnya sesuai aturan ( sistem akan terus melakukan proses diagnosa). Solusi KDPenyakit, sistem akan berhenti menampilkan pertanyaan beserta pilihan gejala dan menampilkan hasil diagnosa berupa nama penyakit dan gejala sesuai pilihan user.Berdasarkan solusi pada aturan tersebut, maka sistem dapatmemutuskan apakah sistem berhenti melakukan proses diagnosa atau lanjut melakukan proses diagnosa proses tersebut.

\section{PERANCANGAN}

\subsection{Perancangan Basis Data}

Pengetahuan disusun dalam bentuk tabel untuk mempermudah sistem dalam mengambil keputusan.Seluruh tabel saling berhubungan dan relasi antara tabel dapat dilihat pada gambar di bawah ini: 
Tabel 5.1 User.dbf

\begin{tabular}{|l|l|l|l|}
\hline \multicolumn{1}{|c|}{ Field Name } & Type & \multicolumn{1}{c|}{ Size } & Key \\
\hline Id_user & A & 10 & \\
\hline Password & A & 8 & \\
\hline
\end{tabular}

Tabel 5.2 Penyakit.dbf

\begin{tabular}{|c|l|l|l|}
\hline Field Name & Type & \multicolumn{1}{|c|}{ Size } & \multicolumn{2}{c|}{ Key } \\
\hline Kd_Penyakit & A & 6 & $*$ \\
\hline Nm_Penyakit & A & 50 & \\
\hline
\end{tabular}

Tabel 5.3 Gejala.dbf

\begin{tabular}{|l|l|l|l|}
\hline \multicolumn{1}{|c|}{ Field } & Type & \multicolumn{1}{c|}{ Size } & \multicolumn{2}{c|}{ Key } \\
\hline Kd_Gejala & A & 6 & $*$ \\
\hline Nm_Gejala & A & 50 & \\
\hline Record & I & & \\
\hline
\end{tabular}

Tabel 5.4 Deteksi.dbf

\begin{tabular}{|l|l|l|l|}
\hline Field Name & Type & Size & Key \\
\hline Kd_Penyakit & A & 6 & $*$ \\
\hline Nm_Penyakit & A & 50 & \\
\hline
\end{tabular}

Tabel 5.5 Solusi.dbf

\begin{tabular}{|l|l|l|l|}
\hline Field Name & Type & Size & Key \\
\hline Gejala & M & 240 & \\
\hline Penyakit & M & 240 & \\
\hline Keterangan & M & 240 & \\
\hline Pencegahan & M & 240 & \\
\hline Record & I & & \\
\hline
\end{tabular}

\subsection{Perancangan Sistem}


AI merupakan sistem dengan basis pengetahuan yang dinamis, dimana pengetahuan itu dapat berubah seiring dengan berjalannya waktu (teori certainty factor) sehingga harus dapat dilakukan pembaharuan seperti penambahan, penghapusan maupun perubahan terhadap data yang sudah disimpan sebelumnya tanpa harus mengubah isi dari program secara keseluruhan. Perubahan hanya dilakukan pada bagian basis pengetahuan saja sehingga aplikasi AI ini dapat dikembangankan lebih lanjut.Tahapan analisis terhadap suatu sistem dilakukan sebelum tahapan perancangan, hal ini agar perangkat lunak yang dirancang sesuai dengan masalah yang akan diselesaikan. Pada tahapan ini peneliti menggunakan beberapa tool-tools pendukung dalam menganalisa logika database program dan tampilan program sehingga aplikasi ini dapat menjadi aplikasi yang memberikan informasi yang tepat bagi user-nya. Beberapa tools yang digunakan yaitu :

\section{KESIMPULAN}

1. Sistem Pakar ini diharapkan mampu untuk menggantikan peran dan fungsi dari pakar maupun literatur dalam masalah hama penyakit pada tanaman aglaonema. Sehingga apabila nantinya pakar masalah hama penyakit tanaman aglaonema tidak ada, atau tidak ditemukan sebuah literatur mengenai hama penyakit tanaman aglaonema, maka proses untuk mengetahui tentang masalah hama penyakit tanaman aglaonema tidak akan terpengaruh sama sekali.

2. Sistem Pakar ini diharapkan mampu memberikan alternatif bagi para pemerhati masalah hama penyakit aglaonema untuk tidak tergantung sepenuhnya terhadap referensi maupun buku-buku tentang masalah hama penyakit tanaman aglaonema mengalami kesulitan dalam mendapatkan referensi dan buku-buku tersebut, maka para pemerhati masalah tersebut masih bisa mendapatkan informasi tentang permasalahan hama penyakit tanaman aglaonema beserta solusi pengendaliannya melalui sistem pakar yang ada.

3. Metode penelusuran yang dipakai dalam pembuatan sistem pakar ini adalah forward chaining, dimana pertanyaan dan fakta akan dicari terlebih dahulu sebelum mendapatkan kesimpulan akhir.

4. Pembuatan sistem pakar ini tidak hanya berpijak pada software yang menggunakan bahasa deklaratif sistem pakar, akan tetapi dengan hasil yang telah didapatkan dari tugas akhir ini, maka Visual basic 6.0 dapat dijadikan sebuah solusi pilihan dalam pengembangan sistem pakar yang lainnya. Selain itu Visual Basic 6.0 juga memberikan kemudahan dalam menciptakan suatu aplikasi sehingga waktu yang diperlukan akan semakin singkat.

\section{DAFTAR PUSTAKA}

“Aglaonema”, TRUBUS. Vol.04

ANDI .2003. Pengembangan Sistem Pakar Menggunakan Visual Basic. Yogyakarta:

Arhami, Muhammad . 2005. Konsep Dasar Sistem Pakar. Yogyakarta: ANDI 
Junaedhie, Kurniawan .2006. Panduan Praktis Perawatan Aglaonema. Jakarta: Agromedia Pustaka

Ladjamudin, Al-Bahra bin. 2000. Analisa dan Desain Sistem Informasi

Nugroho, Bunafit. 2004 VISUAL BASIC. Yogyakarta: Gava Media

Yusnanto. 2003. Pemrograman Dasar Visual Basic 6.0. Surabaya: PRESTASI PUSTAKA 